\title{
Chemical Composition and Nutritional Value of Paddy Straw Milky Mushroom (Calocybe indica)
}

\author{
G. Chelladurai*, T.K. Yadav $* *$ and R.K. Pathak $\dagger^{*} * * *$ \\ *PG \& Research Department of Zoology, Bishop Heber College (Autonomous), Trichy-620017, Tamil Nadu, India \\ **Centre for Environmental Studies, Institute of Interdisciplinary Studies, University of Allahabad, \\ Allahabad-211002, India \\ ***Centre for Biotechnology, Institute of Interdisciplinary Studies, University of Allahabad, Allahabad-211002, India \\ $\dagger$ Corresponding author: Ravi Kant Pathak; pathakravi68@gmail.com
}

Nat. Env. \& Poll. Tech.

Website: www.neptjournal.com

Received: $12-10-2020$

Revised: 24-11-2020

Accepted: $18-12-2020$

\section{Key Words:}

Milky mushroom

Biochemical composition

Cultivation techniques

Paddy straw

Nutritional value

\begin{abstract}
The edible milky mushroom is the most widely cultivated mushroom in tropical and sub-tropical regions. Studies were conducted on the cultivation and nutritional analysis of this mushroom. The pure culture of Calocybe indica was carried out in the laboratory. The culture was maintained on potato dextrose agar slant and sub-cultured at a regular monthly interval to sustain their fruiting vigor. The above stock culture was used in studies. Wheat grain spawn of $C$. indica was prepared in glass bottles. The filled paddy grain spawn of $C$. indica was used at $6 \%$ level to the wet weight of the substrate and the beds were spawned. After harvest, the mushrooms were dried at $40^{\circ} \mathrm{C}$ under the hot air oven to make it powered for further analysis. The collected fresh mushrooms were dried in shade and coarse powder was analyzed for nutrients namely moisture, crude protein, lipid, ash, crude fiber, and minerals. It shows the dominant compounds of protein, fiber, and carbohydrate and the contents are $14.11 \%$, $8.30 \%$ and $5.62 \%$ respectively. Lipid, ash, ether extract and $\mathrm{p}^{\mathrm{H}}$ contents are $4.06 \%, 7.04 \%, 3.15 \%$ and $5.4 \%$ respectively. The carbon and nitrogen contents are $33.60 \%$ and $3.56 \%$ respectively. In the estimation of saturated fatty acids and unsaturated fatty acids present in $C$. indica, totally, 17 fatty acids were recorded. In the estimation of essential and non-essential amino acids present in $C$. indica, totally, 15 amino acids were recorded. In the estimation of minerals composition present in $C$. indica, it was recorded that the species had a good resource of mineral composition. Totally, 6 macro minerals and 8 micro minerals were recorded. This investigation may provide that the paddy straw substrates can be recommended for the commercial cultivation of $C$. indica to obtain highly nutritious mushrooms.
\end{abstract}

\section{INTRODUCTION}

Mushrooms can be used as food to solve malnutrition problems. Mushrooms have good nutritional value particularly as a source of protein that can enrich human diets, especially in some developing countries where animal protein may not be available and are expensive (Gopinath et al. 2012). Many genera of mushrooms are edible and rich in essential nutrients such as carbohydrates, proteins, vitamins, minerals, fat, fibers, and various amino acids (Okwulehie \& Odunz 2000). The Calocybe indica is an easily cultivable edible mushroom in India. They are distributed in the tropical regions of the world. In India, it is widely distributed in the genetic plains of West Bengal. They are considered to be more popular because of their robust size, attractive color, sustainable yield, delicious taste along with its unique texture. It has become the third commercially grown mushroom in India, after the button and oyster's mushroom (Purakayasatha \& Nayak 1979). The bioactive potential of some commercially important mushrooms like milky and button mushroom is a source of essential amino acids and fatty acids for infants and the elderly (Nakalem \& Kabasa, 2013).

The annual production of the milky mushroom in seasonal farms concentrated in the southern states of Tamil Nadu, Kerala and Karnataka have now been estimated to be nearly 10,000 tons. It is purely of Indian origin and highly suitable for the tropical climatic conditions of central India, northern India, and southern India. Its cultivation is now spreading very fast in many states of the country like Tamil Nadu, Kerala, Odisha, Haryana, and West Bengal due to its longer shelf life and adaptability to warm and humid conditions. In Tamil Nadu, this mushroom is commonly grown in sunken beds where humidity and temperatures are ideal for vegetative growth and fruit body development. Mushroom species have been shown to possess antioxidant capacity in in-vitro systems. Like other matrices containing antioxidant compounds, e.g. phenolics, organic acids, and alkaloids from mushrooms can be used both as a food supplement and in the pharmaceutical industry. The public is becoming 
increasingly aware of problems with the over-prescription and misuse of traditional antibiotics (Mary \& Sahana 2014). C. indica is more popular due to its robust size, attractive color, sustainable yield, delicious taste, and unique texture. It is rich in carbohydrates, protein, lipids, fats, fiber, ash, and essential amino acids (Mary \& Sahana 2014). They have become an attractive functional food mainly because of their biochemical composition and antioxidant properties which have been reported to prevent oxidative damage by free radical and reactive oxygen species (ROS) and may prevent the occurrence of diseases like carcinogenesis, aging, physical injury, infection, and cardiovascular disease. Therefore, the milky mushroom is considered a better proxy for oyster mushroom. The aim of this investigation was to analyze the biochemical composition and nutritional values of this mushroom cultivated on a paddy straw bed, to increase awareness of the beneficial effects of edible mushrooms among the consumers.

\section{MATERIALS AND METHODS}

\section{Culture and Maintenance}

The pure culture of $C$. indica was cultivated from the Zoology research laboratory, Kamaraj College, Tuticorin. The pure culture was maintained on the potato dextrose agar slant and sub-cultured at a regular monthly interval to sustain their fruiting vigor. They were stored at $4^{\circ} \mathrm{C}$ for further usage.

\section{Spawn Preparation}

The wheat grain spawn of $C$. indica was prepared in glass bottles as described (Pani 2011a). The wheat grain (1kg) was semi-boiled, then $2 \%$ calcium carbonate and $0.2 \%$ gypsum were added. The mother culture was prepared in glass bottles filling them $1 / 2$ full and the working spawn was prepared in plastic bags capped with cotton plugs by rubber bands. The mother culture was then subcultured on potato dextrose agar and after its full growth, it was transferred to the working spawn bags of $C$. indica.

\section{Cultivation and Harvesting}

The paddy straws were collected from local farmers of the Tuticorin district, Tamil Nadu, India. The straw was used as a substrate for cultivation. The substrate was soaked in cold water for $4 \mathrm{~h}$. After draining excess water, the materials were treated in hot water $\left(80^{\circ} \mathrm{C}\right)$ for 60 mins and dried in shade. For the bed preparation, polythene bags of $60 \times 30 \mathrm{~cm}$ size and 100 gauge thickness was used and cylindrical beds were prepared using $0.5 \mathrm{~kg}$ of substrate (dry weight) per bed. The filled wheat grain spawn of $C$. indica was used at $6 \%$ level to the wet weight of the substrate (Pani 2011b). After 10 to 15 days, when the beds were fully colonized by the mycelium of $C$. indica (mushroom), they were cut into two halves and applied with casing soil to a height of about $2 \mathrm{~cm}$ over the spawn run. The beds were uniformly and regularly sprayed with water until it was the last harvest. In total, three crops were harvested at intervals of 3 to 5 days.

\section{Nutritional Status of $C$. indica}

The collected fresh mushrooms were shade dried and its coarse powder was analyzed for the presence of nutrients namely, protein, fat, ash, fiber, moisture, and minerals.

\section{Estimation of Protein}

Five grams of grounded mushroom was mixed with $50 \mathrm{~mL}$ of $0.1 \mathrm{~N} \mathrm{NaOH}$ and then boiled for 30 mins. After cooling the solution to room temperature, it was subjected to centrifugation at $1000 \mathrm{rpm}$. The supernatant was analyzed for total protein contents (Lowry et al. 1951).

\section{Estimation of Lipid}

The total lipid was determined by a slightly modified method (Floch et al. 1956). Primarily, five grams of finely ground mushroom was suspended in $50 \mathrm{~mL}$ of chloroform: methanol (2:1 v/v) mixture. After mixing thoroughly, it was allowed to stand for 3 days. Then the solution was filtered and centrifuged at $1000 \mathrm{rpm}$ for $15 \mathrm{mins}$.

\section{Estimation of Fiber}

The total fiber contents were determined by the following method (Raghuramulu et al. 2003). Ten grams of moisture and fat-free sample was taken in a beaker. To which $200 \mathrm{~mL}$ of con $0.255 \mathrm{~N} \mathrm{H}_{2} \mathrm{SO}_{4}$ was added and boiled for 30 mins. While boiling, constant volume was maintained by adding water at frequent intervals. Then, it was filtered through a muslin cloth and the residues were washed with hot distilled water for the complete removal of acid from it. After which, it was transferred to the same beaker and $200 \mathrm{~mL}$ of 0.313 $\mathrm{N} \mathrm{NaOH}$ was added to it. After boiling it for $30 \mathrm{mins}$, the mixture was filtered through a muslin cloth then, and the residues were washed thoroughly in hot water until it was freed from alkali. It was then washed with ethyl alcohol and followed by ether. Finally, it was transferred to a crucible, dried overnight at $80^{\circ} \mathrm{C}$ to $100^{\circ} \mathrm{C}$ and its weight was recorded in an electric balance. The crucible was heated in a muffle furnace at $600^{\circ} \mathrm{C}$ for 5 to $6 \mathrm{~h}$ and its weight was recorded after it cooled.

\section{Estimation of Ash}

The ash contents were determined by innerving or burning the pre-weighed test sample ( $1 \mathrm{~g}$ dry weight) in a muffle furnace at $560^{\circ} \mathrm{C}$ for a period of $5 \mathrm{~h}$. Then, the residues were 
weighed and the percentage was calculated according to AOAC (1990). It was subjected to further analysis.

\section{Estimation of Nitrogen and Carbon Contents}

The total nitrogen and carbon contents were determined using the wet digestion extraction methods (Nivozamsky et al. 1983).

\section{Determination of $\mathrm{pH}$}

The $5 \%(\mathrm{w} / \mathrm{v})(5 \mathrm{~g}$ in $100 \mathrm{~mL}$ of water) finely powdered mushroom was kept on a shaker for $5 \mathrm{~h}$ at $140 \mathrm{rpm}$ and then subjected to filtration. The filtrates were analyzed for the $\mathrm{pH}$ using a pH meter (Elico, India) (Iqbal et al. 2010).

\section{Estimation of Amino Acids}

The collected tissues were dried at $60^{\circ} \mathrm{C}$ for $24 \mathrm{~h}$ in an oven and they were packed in airtight polyethylene covers and kept in desiccators. The oven-dried samples were finely ground before estimating the amino acid profile. Amino acids were estimated in HPLC-Lachrome Merck in SPD-10A VP Detector (Baker et al. 1994).

\section{Estimation of Fatty Acids}

The samples were oven-dried at $70^{\circ} \mathrm{C}$ for $24 \mathrm{~h}$ until no more weight reduction was observed. After that, it was ground finely with pestle and mortar. To the $100 \mathrm{mg}$ to $200 \mathrm{mg}$ of finely ground tissue samples, $2 \mathrm{~mL}$ of chloroform and methanol (1:1 ratio) was added and kept aside for $30 \mathrm{sec}$. Then the residual matter was removed through filtration with the Whatman no:1 filter paper $(125 \mathrm{~mm})$. After that, it was subjected to washing with $1 \mathrm{~mL}$ of chloroform and methanol (2:1 ratio) for removing the inorganic substance. Next, the extracts were infected with chloroform: methanol: water $(8: 4: 3)$ where the residual phase was evaporated to dryness. Then the dried matter was sealed in a test tube with $3 \%$ methanolic $\mathrm{HCl}$ and stored at $80^{\circ} \mathrm{C}$ for $18 \mathrm{~h}$. To this, $2 \mathrm{~mL}$ of hexane was added for extraction of the fatty acid ethyl esters from the methanol by hexane. $1 \mathrm{~mL}$ of the supernatant containing hexane phase was collected in a microvel. After which, the residual fraction was dissolved in the ratio of 10:1 with ethyl acetate and 1:1 aliquot of which was injected into gas chromatography equipped with flame identification detector and column HP ULTRA -2 (25 m, 0.2 mm 1D) (Babu et al. 2012).

\section{Estimation of Minerals}

The concentration of the metals like calcium, sodium, magnesium, potassium, phosphorous, barium, iron, zinc, cobalt, chromium, copper, manganese, gallium, lithium, nickel, selenium, aluminum, and boron, were estimated from $1 \mathrm{~g}$ of mechanically ground and oven-dried samples at $175^{\circ} \mathrm{C}$. Then it was digested with sulphuric acid and $40 \%$ nitric acid and was allowed to stand overnight at room temperature, before being analyzed for specific metals, using Atomic Absorption Spectrophotometer (AAS) Shimadzu -AA-65015 (Guzman \& Jimenez 1992).

\section{RESULTS AND DISCUSSION}

\section{Cultivation of $C$. indica}

On casing the spawn bed into the soil, a small mushroom is developed which is shown in Fig. 1. After 4 days the mushroom growth is increased to $5-6 \mathrm{~cm}$ in length. It's ready to harvest. After harvest, the mushroom was dried at $40^{\circ} \mathrm{C}$ under the hot air oven to make it powered for further analysis (Fig.1).

\section{Proximate Composition of $C$. indica}

The results of the proximate and nutritional composition
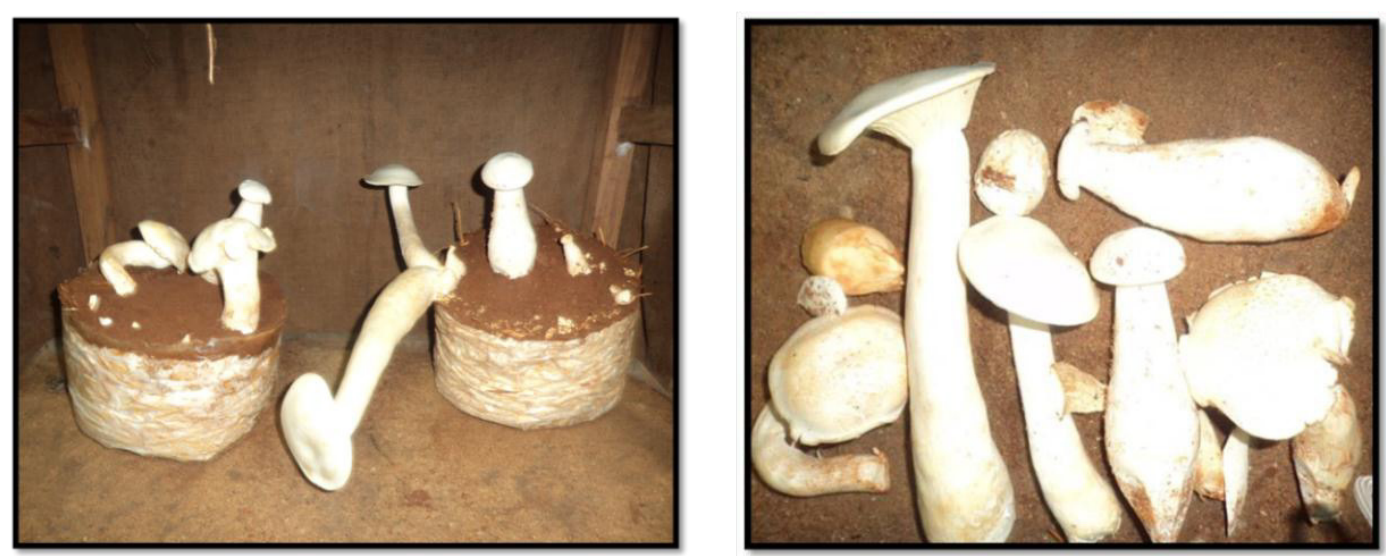

Fig. 1: Harvesting stage of $C$. indica. 
of dried $C$. indica are shown in Fig. 2. It shows that the dominant compounds are protein $(14.11 \%)$, fiber $(8.30 \%)$, carbohydrate $(5.62 \%)$, lipid $(4.06 \%)$, ash $(7.04 \%)$, ether extract $(3.15 \%)$, and $\mathrm{pH}(5.4 \%)$. The carbon and nitrogen content of $C$. indica are (33.60\%) and (3.56\%) respectively (Fig. 2).

\section{Fatty acids profile of $C$. indica}

In the estimation of saturated fatty acids and unsaturated fatty acids present in $C$. indica, a total of 17 fatty acids were recorded. Among the available saturated fatty acids (SFA) include stearic acid (20.36\%), lignoceric acid (1.57\%), myristic acid (1.49\%), lauric acid (1.42\%), palmitic acid (1.30\%), heneicosylic acid $(0.41 \%)$, pentadecyclic acid $(0.65 \%)$, margaric acid $(0.27 \%)$, and arachidic acid $(0.28 \%)$ (Fig. 3a). The unsaturated fatty acids include linoleic acid $(42.88 \%)$, elaidic acid $(22.47 \%)$, myristoleic acid $(1.56 \%)$, eicosapentaenoic acid $(1.86 \%)$, erucic acid $(0.34 \%)$, palmitoleic acid $(0.21 \%)$, gondoic acid (1.24\%), and dichomo-linolenic acid $(0.657 \%)$ (Fig. 3b). In the analysis of fatty acids, it was observed that

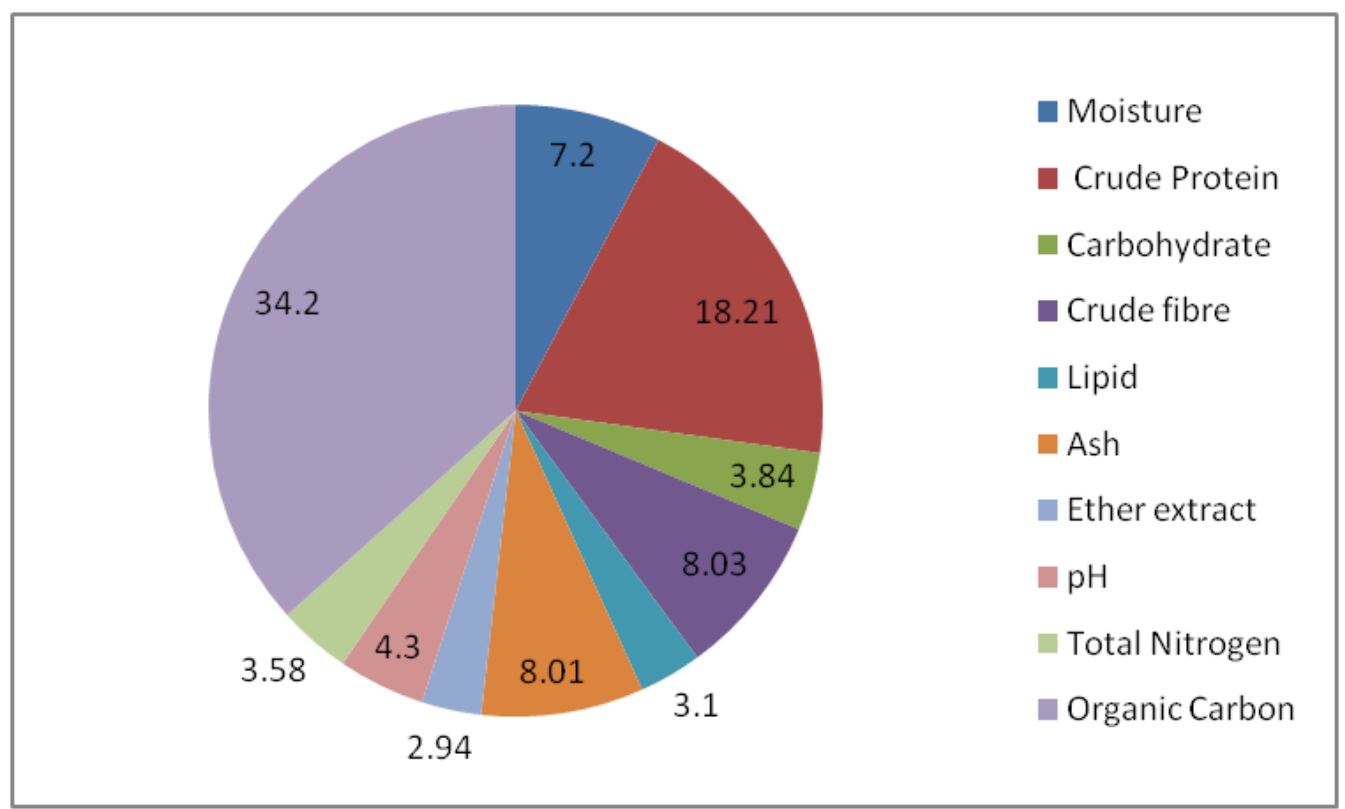

Fig. 2: Proximate composition of $C$. indica.

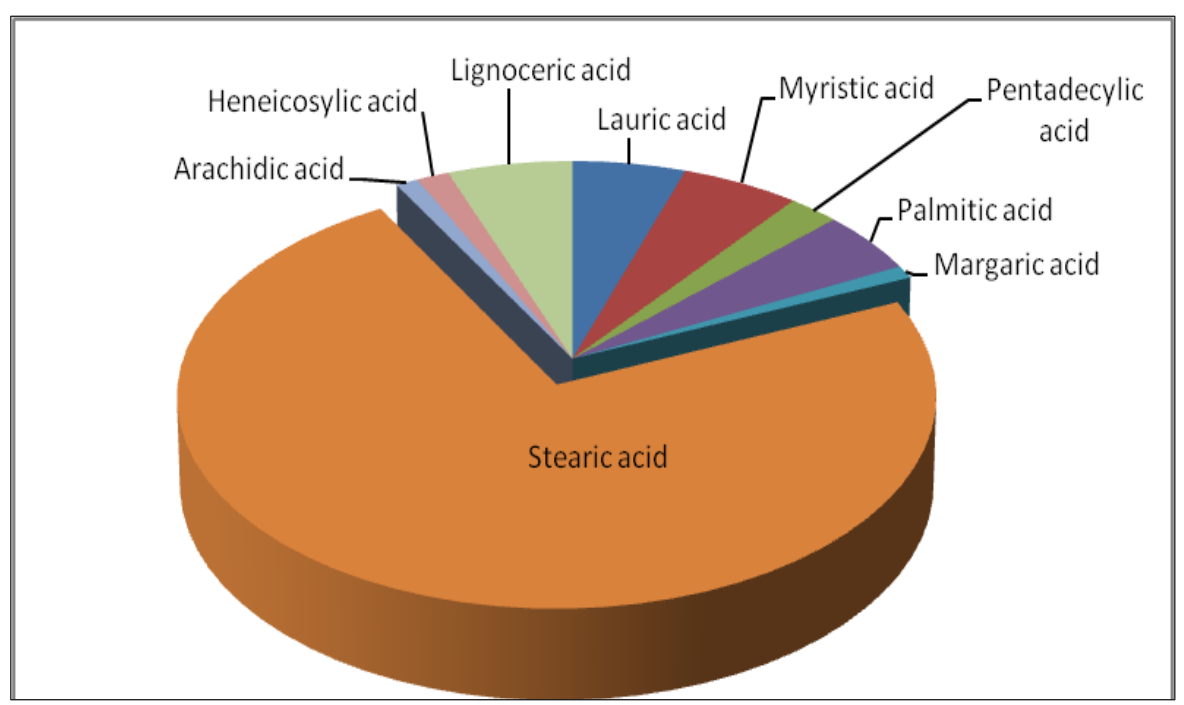

Fig. 3a: Composition of saturated fatty acids of $C$. indica. 
the most abundant fatty acids present in the $C$. indica were linoleic acid and elaidic acid.

\section{Amino acids content of dried $C$. indica}

In the estimation of essential and non-essential amino acids present in dried powder of $C$. indica, totally 15 amino acids were recorded. Among the non-essential amino acids, analine was found to be the most abundant amino acids followed by glutamic acid and Isoleucine. Among the essential amino acids, isoleucine (12.37\%), histidine (8.07\%), leucine $(5.17 \%)$, valine $(4.33 \%)$, threonine $(3.70 \%)$, lysine $(2.26 \%)$, phenylalanine $(2.29 \%)$ and methionine $(0.27 \%)$ were recorded (Fig. 4a). The non-essential amino acids like analine $(16.05 \%)$, glutamic acid $(14.75 \%)$, aspartic acid (11.85\%), glycine (7.41\%) Serine (6.78\%), tyrasine (3.42\%) and arginine (2.37\%) were recorded (Fig. 4b).

\section{Minerals Composition}

In the analysis of the minerals in dried mushrooms, results show that there is a good source of minerals. Among the minerals totally, 6 macro minerals and 8 micro minerals were recorded. The maximum macro mineral was potassium (28209ppm), followed by magnesium (1012ppm), phosphorus (381ppm), and barium (9.3ppm) were recorded (Fig. 5a). Micro minerals

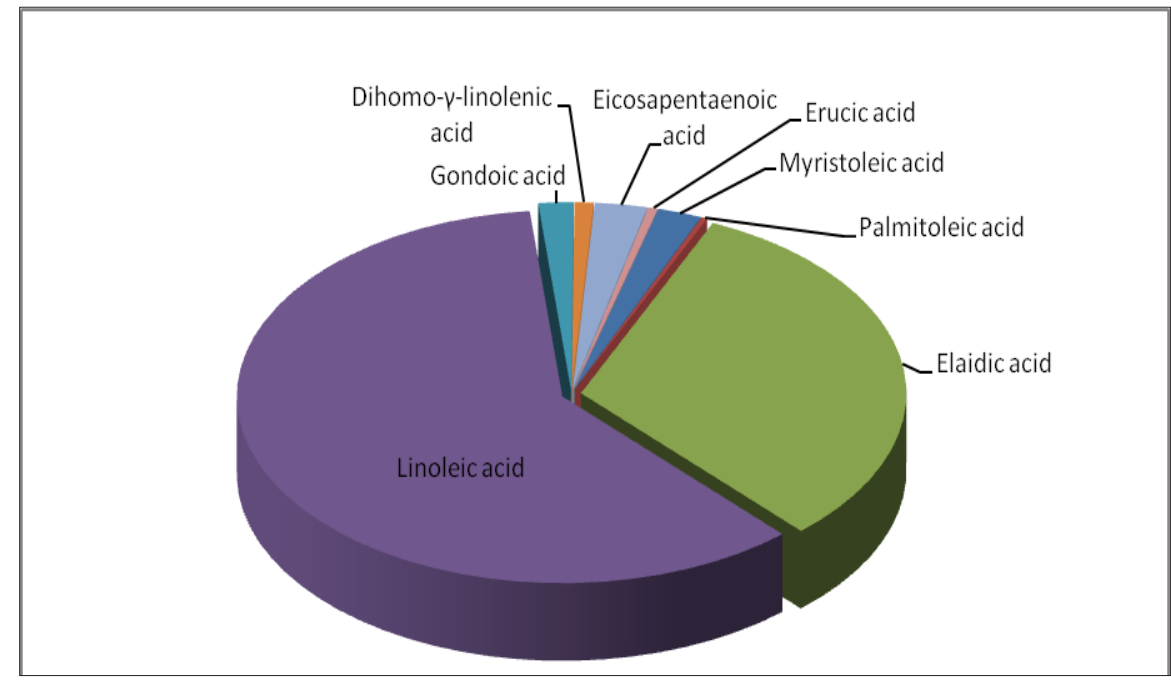

Fig. 3b: Composition of unsaturated fatty acids of $C$. indica.

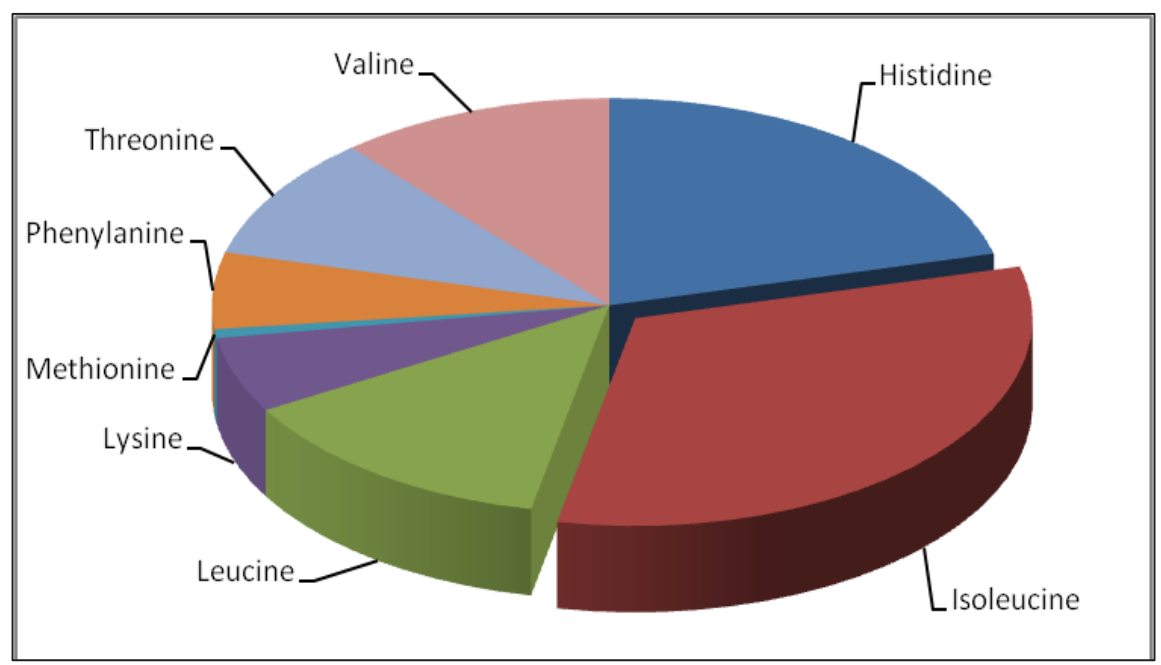

Fig. 4a: Composition of essential amino acids of $C$. indica. 


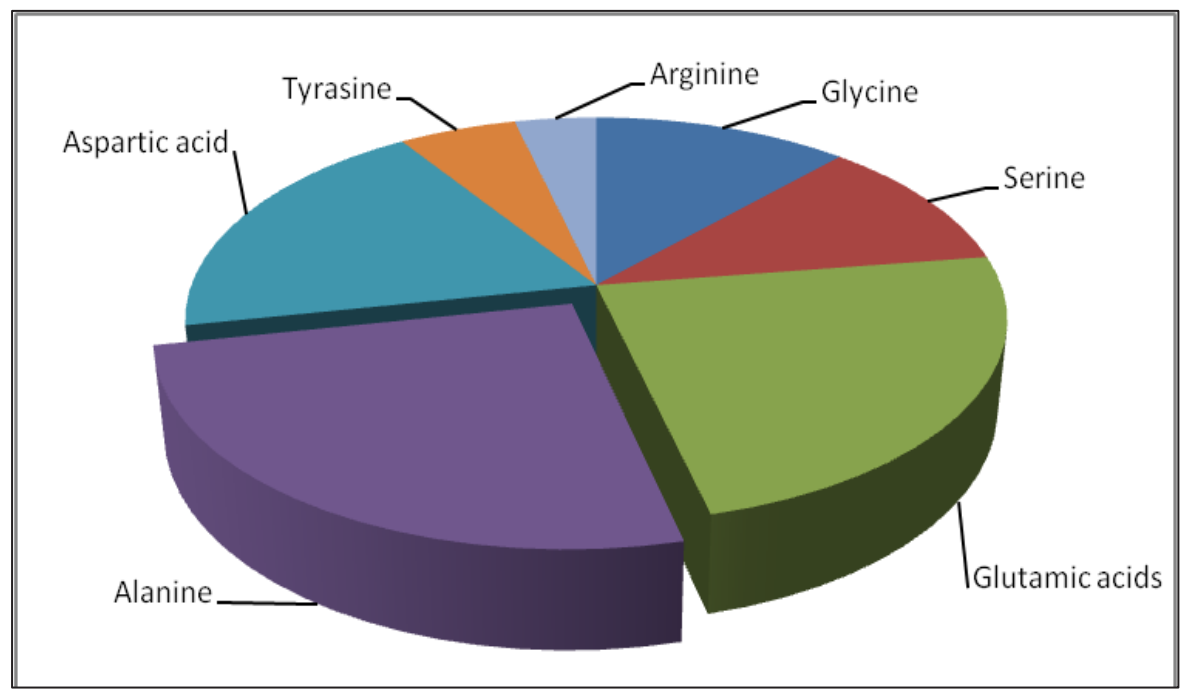

Fig. 4b: Composition of non-essential amino acids of $C$. indica.

such as iron (77.55ppm), aluminum (38.92ppm), manganese (20.56ppm), copper (28.20ppm), zinc (35.12ppm), boron (18.87ppm), nickel (0.85ppm), chromium $(0.89 \mathrm{ppm})$ were recorded (Fig. 5b).

\section{DISCUSSION}

The $C$. indica (Milky Mushroom) could be easily grown on a wide range of substrate including the straw of paddy, wheat, ragi, maize, bajra, cotton stalks, and leaves, sugarcane biogases, cotton and jute wastes, dehulled maize cobs, tea/coffee waste, etc. Saranya et al. (2011) investigated the cultivation of milky mushrooms, $C$. indica, which was conducted to find out the growth and yield performance on different substrates. The yield of fresh mushroom obtained from paddy straw, teak leaves, and sugarcane trash substrates were 1140, 745, and $570 \mathrm{~g} . \mathrm{kg}^{-1}$ respectively. The nutritional significance of $C$. indica cultivated on different substrates was assessed in terms of protein, carbohydrate, amino acids, and lipids. The cellulolytic activity and coir pith compost were also tested using C. indica. The present result suggested the lignocellulosic substrate like paddy straw, teak leaves, and sugarcane trash show great potential for use as a raw material since this substrate provides an economically acceptable production for $C$.

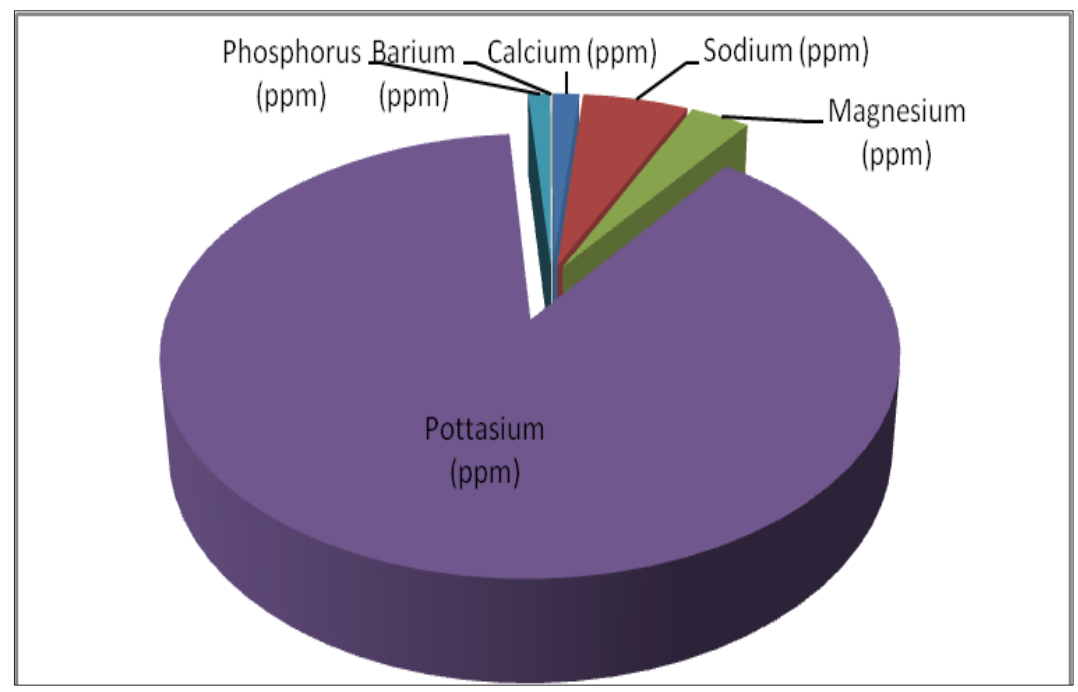

Fig. 5a: Composition of macro minerals of $C$. indica. 


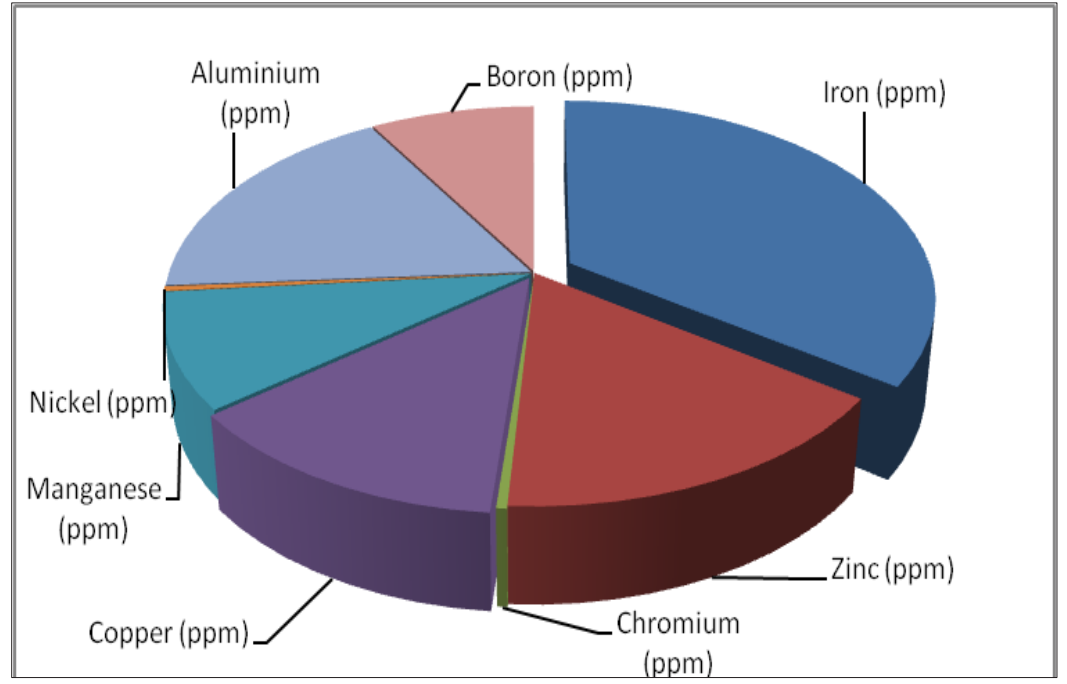

Fig. 5b: Composition of micro minerals of $C$. indica.

indica. Mushrooms are neutraceuticals which contain edible fruit body. The nutritive value of mushrooms is equal to that of milk and it has low calories, sodium, fats, and cholesterol. In addition to this, they are rich in protein, unsaturated fatty acids, vitamin B, D, C as well as minerals such as potassium, phosphorus, calcium, and magnesium. (Krishnaveni et al. 2014). The high yield strain of $C$. indica grows well at room temperature between $24^{\circ} \mathrm{C}$ to $27^{\circ} \mathrm{C}$ and can be cultivated even on unfermented materials. The advantages of this mushroom over other mushrooms are easy method of cultivation, less investment, very attractive fruiting body, pleasing milk-white color, long shelf life, more nutritious and less time to grow (Kathiravan \& Krishnakumari 2015). In the present study, the cultivation of $C$. indica was carried out on paddy straw waste and has been observed to produce an excellent yield after 15 days.

Mushrooms are a good source of digestible proteins and less fat in nature. The present study also reveals that the nutritional composition of $C$. indica was protein (14.11\%), fiber $(8.30 \%)$, carbohydrate $(5.62 \%)$, fat $(4.06 \%)$, ash $(7.04$ $\%)$, ether extract $(3.15 \%), \mathrm{p}^{\mathrm{H}}(5.4)$, carbon $(33.60 \%)$ and nitrogen $(3.56 \%)$. Mushrooms contain higher nutritional values of protein $(4.22 \mathrm{~g})$, carbohydrate $(1.11 \mathrm{~g})$, fat $(1.05 \mathrm{~g})$, ash $(2.30 \mathrm{~g})$, and moisture (85.95) (Krishnamoorthy et al. 1998). Mushrooms consist mostly of unsaturated fatty acids, which are less hazardous to the health than the saturated fatty acids of animal fats (Zahid et al. 2010). The moisture percentage depends on the mushroom species and the parameters related to harvest, culinary, and storage conditions. Mushrooms also contain a rich amount of amino acids (Kalac 2013). Leucine, valine, glutamic, and aspartic acid are the most abundant amino acids in mushrooms (Guillamónet et al. 2010). The present study with $C$. indica showed 8 essential and 7 non-essential amino acids. The amino acid aniline $(16.05 \%)$ was served to be the most significant and it's followed by glutamic acid $(14.75 \%)$ and isoleucine $(12.37 \%)$. Mushrooms can be used as food to solve malnutrition problems. Mushrooms have good nutritional value particularly as a source of protein that can enrich human diets, especially in some developing countries where animal protein may not be available and are expensive (Proksch et al. 2002). The presence of linoleic acid and oleic acid were observed to be the major unsaturated fatty acid present in $C$. indica. Usually, in mushrooms, the fat contents seem to be very low when compared with proteins and carbohydrates. Moreover, the fats present in the mushroom fruiting bodies are dominated by unsaturated fatty acids. In the present study, 17 fatty acids were recorded. From the analysis of fatty acids, it was observed, the most abundant fatty acids present in the C. indica were linoleic acid $(42.88 \%)$ followed by elaidic acid $(22.47 \%)$. Mushrooms are considered to be a dietary supplement for aquaculture because of their higher protein contents when compared with that of fats.

Sodium, magnesium, potassium, and calcium are the essential macronutrient absorption in the intestine and are used for their normal metabolism (Satish et al. 2013). Their imbalance would result in the diseased or infected conditions exhibiting their significant impact on the immune system of Babylonia spirata. The present study on the minerals composition of $C$. indica revealed the presence of 6 macro minerals and 8 micro minerals, among them, potassium (28209 $\mathrm{ppm})$ as maximum in macro minerals and iron (77.55ppm) 
as maximum in micro minerals. Similarly, the nutraceutical properties of $C$. indica have reported the presence of vitamins, proteins, minerals, amino acids, polyphenols such as flavonoids and alkaloids (Mirunalini et al. 2012).

Mushroom seems to be an important source of bioactive compounds for the development of new therapeutic agents (Sumathy et al. 2015). Since mushrooms are abundant in nature, cost-effective, and easily can be cultivated, there is a promising solution for a variety of health issues in the upcoming years. These data suggest that dietary mushrooms cultivated on paddy straw are a good source of nutrients especially minerals and fatty acids. So, this result also indicates that the studied mushrooms have good nutritive value for humans. In addition, mushrooms are a promising food that may overcome the protein-energy malnutrition problem in the nation.

\section{ACKNOWLEDGEMENTS}

The authorities of Kamaraj College, Manonmaniam Sundaranar University for providing the necessary facilities, and the author, in addition, thank the Centre for Marine Living Resources and Ecology (CMLRE), Project (Grant No. MoES/10-MLR/01/12), Government of India for their financial support.

\section{REFERENCES}

AOAC 1990. Official Method of Analysis (15th Edition). Association of Official Analytical Chemists, Washington DC, U.S.A.

Babu, A.V., Venkatesan, M. and Rajagopal, S. 2012. Biochemical composition of different body parts of Gafrarium tumidum (Roding 1798) from Mandapam, South East Coast of India. Afr. J. Biotechnol., 11(7): 1700-1704

Baker, D.H. and Han, Y. 1994. Ideal amino acid profile for broiler chicks during first three weeks post-hatching. Poult. Sci.,73: 1441-1447.

Floch, J., Lees, M. and Sloane-Stanley, G.H. 1956. A simple method for the isolation and purification of total lipids from animal tissues. J. Biol. Chem., 226: 497-509.

Gopinath, L., Arunkumar, J., Meera, A. and Shantha, P.R. 2012. Optimization of growth parameters for increased yield of the edible mushroom Calocybe indica. Afr. J. Biotechnol., 11(11): 7701-7710.

Guillamón, E., García-Lafuente, A., Lozano, M., D’Arrigo, M., Rostagno, M.A., Villares, A. and Martínez, J.A. 2010. Edible mushrooms: Role in the prevention of cardiovascular diseases. Fitoterapia, 81: 715-723.

Guzman, H.M. and Jimenez. 1992. Concentration of coral reefs by heavy metals along the Caribbean coast of central Africa (Costarica and Panama). Mar. Pollut. Bull., 24: 554-561.

Iqbal, Z., Lateef, M., Jabbar, A. and Gilani, A. H. 2010. In vivo anthelmintic activity of Azadirachta indica A. Juss seeds against gastrointestinal nematodes of sheep. Vet. Parasitol., 168: 342-345.
Kalac, P. 2013. A review of the chemical composition and nutritional value of wild-growing and cultivated mushrooms. J. Sci. Food Agric., 93(2): 209-218.

Kathiravan, S. and Krishnakumari, S. 2015. Optimization of casing process for enhanced bioefficiency of Calocybe indica, an indigenous tropical edible mushroom. Int. J. Rec. Sci. Res., 6(2): 2594-2598.

Krishnamoorthy, A.S., Muthusamy, M., Marimuthu, T., Narasimhan, V. and Muthusankaranaraynman, A. 1998. Milky mushroom, APK 2. Bulletin on new mushroom variety release. Regional Research Station, TANU, Aruppukottai, India. 16.

Krishnaveni, M. and Saranya, R. 2014. Cultivation of Pleurotus florida and Calocybe indica using various agrowaste. Res. J. Pharm. Technol., 7(3): 307- 309.

Lowry, O.H., Rosebrough, N.J., Farr, A.L. and Randall, R.J. 1951. Protein measurement with the tolin phenol reagent. J. Biol. Chem.,193: 265273.

Mary, J. and Sahana, B. 2014. Cultivation of milky mushroom using paddy straw waste. Int. J. Curr. Microbiol. Appl. Sci., 3(12): 404-408.

Mirunalini, S., Dhamodharan, G. and Deepalakshmi. K. 2012. Antioxidant potential and current cultivation aspects of an edible milky mushroom-Calocybe indica. Int. J. Pharm. Sci., 4(1): 137-143.

Nakalem, B. and Kabasa, J.D. 2013. Fatty and amino acids composition of selected wild edible mushrooms of Bunyoro sub-region, Uganda. AJFAND, 13(1): 7225-7240.

Nivozamsky, I., Houba, V.J.G., Van Eck, R. and Van Vark, W. 1983. A novel digestion technique for multi-element plant analysis. Commun. Soil Sci. Plant Anal., 14: 239-248.

Okwulehie, I.C. and Odunze, E.I. 2000. Evaluation of the nutritional value of some tropical edible mushrooms. J. Sustain. Agric. Environ., 6(2): $157-162$.

Pani, B.K. 2011a. Response of summer white mushroom (Calocybe indica) to supplementation of cultivation substrate. Asian J. Exp. Biol. Sci., 2(4): 766-768.

Pani, B.K. 2011b. Evaluation of straw of some paddy varieties as substrates for cultivation of milky mushroom (Calocybe indica) in Orissa. Biosci. Discov., 2(3): 341-342.

Proksch, P., Edrada R.A. and Ebel, R. 2002. Drug form the seas-current status and microbiological implication. Appl. Microbiol. Biotechnol., 59: $125-134$.

Purakayasatha, R.P. and Nayak, D. 1979. A new method of cultivation of Calocybe indica: An edible mushroom. Taiwan Mushroom, 3: 14-18.

Raghuramulu, N., Madhavan, N.K. and Kalyanasundaram, S.A. 2003. Manual of Laboratory Techniques. Hyderabad, India: National Institute of Nutrition. Indian Council of Medical Research, pp. 59-58

Saranya, V., Madhanraj, P. and Panneerselvam, A. 2011. Cultivation, composting, biochemical and molecular characterization of Calocybe indica (C and A). Asian J. Pharm. Res., 11(1): 55-57.

Satish, K., Sharma, M., Alok, R. and Abalisha, A. 2013. Effect of various organic supplements on non-enzymatic antioxidant and minerals expression in Calocybe indica. The Biosean, 8(2): 421-424.

Sumathy, R., Kumuthakalavalli, R. and Krishnamoorthy, A.S. 2015. Proximate, vitamin, amino acid, and mineral composition of milky mushroom, Calocybe Indica (P\&C). Var. Apk2 commonly cultivated in Tamil Nadu. J. Nat. Prod. Plant Resour., 5 (1): 38-43.

Zahid, M.K, Barua, S. and Haque, S.M. 2010. Proximate composition and mineral content of selected edible mushroom varieties of Bangladesh. Bangladesh J. Nutr., 22-23: 61-68. 